\title{
Critical Care Management and Monitoring of Intracranial Pressure
}

\author{
Jeremy Ragland, MD and Kiwon Lee, MD, FACP, FAHA, FCCM \\ Division of Critical Care, Department of Neurological Surgery, The University of Texas Health Science Center at Houston, Neuroscience and Neurotrauma \\ Intensive Care Unit, Memorial Hermann Texas Medical Center, The Mischer Neuroscience Institute, Houston, Texas, USA
}

Patients with brain injury of any etiology are at risk for developing increased intracranial pressure. Acute intracranial hypertension is a medical emergency requiring immediate intervention to prevent permanent damage to the brain. Intracranial pressure as an absolute value is not as valuable as when one investigates other important associated variables such as cerebral perfusion pressure and contributing factors for an adequate cerebral blood flow. This manuscript reviews a number of various interventions that can be used to treat acute intracranial hypertension and optimize cerebral perfusion pressure. Management options are presented in an algorithm-format focusing on current treatment strategies and treatment goals. In addition to the efficacy, clinicians must consider significant adverse events that are associated with each therapy prior to initiating treatment. The initial step includes elevation of head of the bed and adequate sedation followed by osmotic agents such as mannitol and hypertonic saline infusion. Hypothermia and pentobarbital therapy represent more aggressive steps, and utilize different mechanisms by which the pressure is controlled, likely causing significant reduction in metabolism. Surgical intervention may precede any medical therapy in order to provide more robust response in controlling intracranial hypertension in certain cases.

\section{J Neurocrit Care 2016;9(2):105-112}

Key words: Intracranial pressure; Intracranial hypertension; Cerebral perfusion pressure; Cerebral blood flow; Hypothermia; Osmotic agents

\author{
Received December 15, 2016 \\ Revised December 16, 2016 \\ Accepted December 16, 2016 \\ Corresponding Author: \\ Kiwon Lee, MD, FACP, FAHA, FCCM \\ Division of Critical Care, Neuroscience \\ and Neurotrauma Intensive Care Unit, \\ The University of Texas Health Science \\ Center at Houston, Memorial Hermann \\ Texas Medical Center, The Mischer \\ Neuroscience Institute, 6431 Fannin St. \\ MSB 7.152, Houston, TX 77030, USA \\ Tel: +1-713-500-6128 \\ Fax: +1-713-500-0665 \\ E-mail: Kiwon.Lee@uth.tmc.edu
}

Copyright $\odot 2016$ The Korean Neurocritical Care Society

\section{INTRODUCTION}

Acute intracranial hypertension (AIH) is defined as sustained intracranial pressure (ICP) greater than $20 \mathrm{mmHg}$ for greater than five to ten minutes in a patient that is not being stimulated. ${ }^{1-3}$ Many disease processes can result in AlH including traumatic brain injury (TBI), large acute ischemic stroke, and intracerebral hemorrhage. The common denominator in all of these disease processes is the expansion in intracranial volume. ${ }^{3}$ Regardless of the cause, $\mathrm{AlH}$ is associated with worse outcomes. ${ }^{4} \mathrm{AlH}$ is a medical emergency that requires rapid diagnosis and treatment to avoid irreversible damage to the brain. Multiple studies have shown improved outcomes and reduced mortality with aggressive treatment of $\mathrm{AlH}^{5-7}$ In this review, pathophysiology of ICP, modalities used to monitor ICP, treatment strategies for patients with $\mathrm{AlH}$, and the therapeutic goals of those treatment strategies are discussed in detail.

\section{PATHOPHYSIOLOGY}

\section{Intracranial compliance}

The Monro-Kellie doctrine states that the intracranial

cc This is an Open Access article distributed under the terms of the Creative Commons Attribution Non-Commercial License (http://creativecommons.org/licenses/by$\mathrm{nc} / 4.0$ ) which permits unrestricted non-commercial use, distribution, and reproduction in any medium, provided the original work is properly cited. 


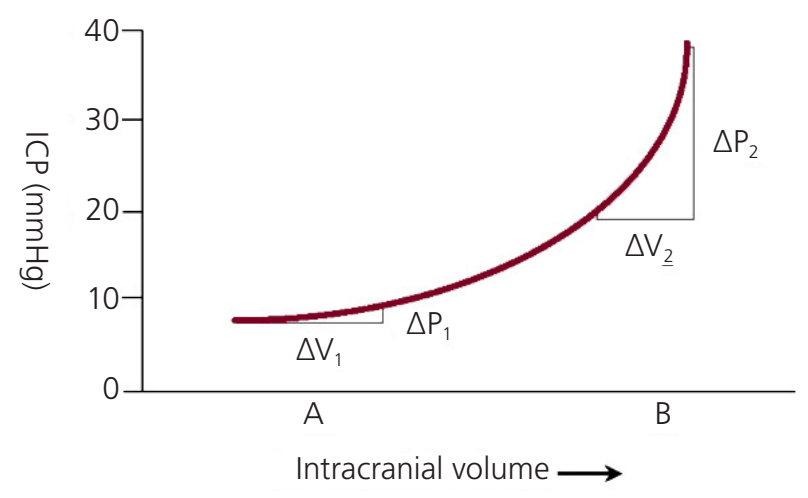

Figure 1. Intracranial pressure - volume relationship.

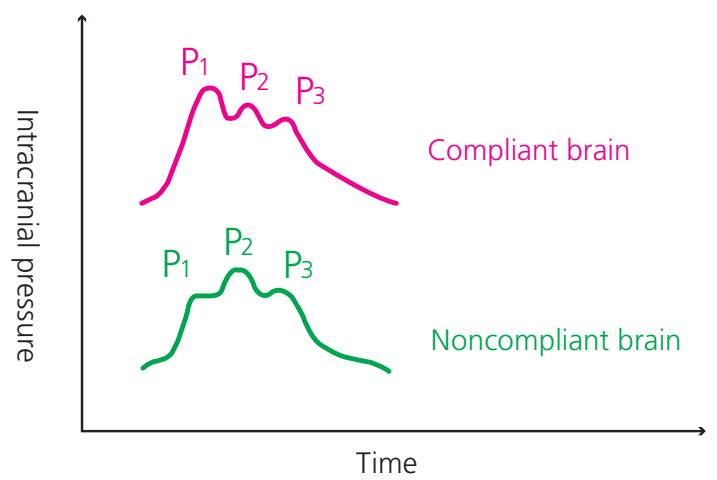

Figure 2. Intracranial pressure waveform. Normal compliance and decreased compliance.

space is a fixed volume inside the skull. ${ }^{3}$ This intracranial space has three components: brain tissue, blood, and cerebrospinal fluid (CSF). In an average adult, the brain tissue volume is 1,400 mL; the blood volume is $150 \mathrm{~mL}$; and the CSF volume is $150 \mathrm{~mL}^{3}$ Normal ICP ranges $3-15 \mathrm{mmHg}$; in the intensive care unit (ICU), ICP values less than $20 \mathrm{mmHg}$ are generally accepted. Pathologic states within the intracranial vault result in an increase of volume. This is a result of at least one of the following: 1) extrinsic mass lesion, 2) increase in blood volume, 3) increase in CSF volume, or 4) increase in brain tissue. To maintain normal ICP in these pathologic states, there is a reduction in the volume of other compartments as a compensatory mechanism. As this compensatory mechanism reaches its limit, the compliance (delta V/delta P) drastically. As compliance decreases, there is a greater the change in pressure for a given change in volume (i.e., there are dramatic changes in pressure for small incremental changes in volume; Fig. 1). This is re- flected in the ICP waveform as seen in Fig. 2.

Cerebral perfusion pressure (CPP) is defined as mean arterial pressure (MAP) minus intracranial pressure (i.e., $C P P=M A P-I C P)$. Therefore as ICP rises, CPP will fall. Normal CPP is $60-150 \mathrm{~mm} \mathrm{Hg} .{ }^{8}$ CPP less than $60 \mathrm{mmHg}$ may result in ischemic brain injury, while CPP greater than 150 $\mathrm{mmHg}$ can lead to hyperemia and hyperperfusion injury.

\section{ICP MONITORING MODALITIES}

\section{External ventricular drain}

An external ventricular drain (EVD) is a catheter inserted into one of the lateral ventricles and connected to an external transducer via tubing filled with saline. In addition to an external transducer, there is also a fluid collection system, and a three-way stopcock allows the clinician to switch between draining fluid and transducing a pressure. The transducer must be positioned at the level of the external auditory meatus (the level of the Foramen of Monro) to accurately measure the intracranial pressure. ${ }^{3}$ The system can be set up to continuously drain fluid with intermittent pressure transduction or to continuously transduce a pressure with intermittent fluid drainage. The advantage of an EVD is that it is both diagnostic and therapeutic. Its major disadvantage is the risk of infection leading to meningitis or ventriculitis. Infection occurs on $10-20 \%$ of patients and this risk increases after about 5 days. ${ }^{9}$ Some catheters are now made with antibiotic coating to help reduce infection rates, but its superiority has not been consistently shown compared to the conventional catheters. Additionally, in some ICUs, it is standard to administer systemic antibiotics during the duration of the time the catheter is in place. In addition to acquiring actual pressure readings, it is also important to pay attention to the ICP waveforms. The second peak of the waveform either at or above the level of the first peak suggests poor brain compliance. When brain compliance is poor - even if the ICP is normal- it is not recommended to put patient's head down flat (e.g. while obtaining CT or MRI images) or wean sedation as it does not take much for ICP to rise above the acceptable level. 


\section{Intraparenchymal pressure monitor}

Intraparenchymal pressure monitors are placed into the brain tissue via a burr hole and secured using bolt. A pressure transducer is incorporated directly into the catheter as opposed to an external transducer as discussed with an EVD. The catheter requires calibration once prior to placement. The accuracy of the ICP measurements is generally better than what is achieved with subarachnoid or epidural monitors, which have fallen out of favor. ${ }^{10}$ One advantage of Intraparenchymal monitors is ease of insertion as one does not need to aim for a particular space as is required with an EVD. A second advantage is a drastically lower infection rate, which on average is around $1 \% .{ }^{11}$ The major disadvantage to this modality is that it only allows for ICP monitoring without a combined therapeutic option of CSF drainage. More recently, there are intraparenchymal pressure monitoring catheters that also contain EVDs and other ports for multimodality probes such as brain tissue oxygen or blood flow catheters.

\section{TREATMENT OPTIONS FOR ACUTE INTRACRANIAL HYPERTENSION}

Many treatment options exist to treat acute intracranial hypertension. The goal of these therapies is to decrease ICP to less than $20 \mathrm{~mm} \mathrm{Hg}$; however, the most recent TBI guidelines from the Brain Trauma Foundation (BTF) suggest that the ICP goal should be less than $22 \mathrm{mmHg} .{ }^{12} \mathrm{~A}$ step-wise algorithm is presented here which provides a standardized approach to the management of $\mathrm{AlH}$. While multiple steps can be instituted as once, no step should be skipped before the initiation of a new step. Furthermore, weaning of therapies should occur in a step-wise fashion as well to avoid rebound ICP crises. Use of a stepwise algorithm in an ICU setting not only allows for wellcoordinated treatment of patients, it also can help improve outcomes. A retrospective study suggests that TBI patients in whom ICP was treated with using a standardized algorithm had fewer interventions and shorter duration of treatment compared to patients treated ad hoc., ${ }^{3,13}$ Prior to proceeding through the algorithm, a set of general measures should be considered. These include elevation of the head of bed to $30^{\circ}$, position of the head in a midline position, initiation of seizure prophylaxis, volume resuscitation, avoidance of hyperglycemia and hyperthermia.

\section{Step 1. Surgical decompression}

The initial step in the management of AlH should always be consideration of whether a surgical intervention such as ventriculostomy or craniectomy with duraplasty should be performed to remove CSF volume or decompress the skull, respectively. Additionally a computed tomography (CT) scan of the head should be obtained to evaluate for increased size of hemorrhage worsening hydrocephalus. If an EVD is already in place, then it should be open to drain CSF. After placement of an EVD, it would be important to always make sure its patency.

For TBI patients, following the initial resuscitation, early ( $<24$ hours) decompressive craniotomy with evacuation of a focal mass lesion is the single most important treatment resulting in improved outcomes. ${ }^{8,14}$

For patients with large hemispheric ischemic strokes, decompressive craniectomy in patients with clinical and radiographic evidence of malignant edema reduces ICP and improves outcome. ${ }^{8,15-18}$ Predictors of poor outcome after decompressive craniectomy for ischemic stroke include age $>60$ years, preoperative GCS $<8$, preoperative anisocoria, early clinical deterioration ( $<72$ hours from stroke onset), and multiple territory infarction. ${ }^{8,19,20}$

In patients with intracerebral hemorrhage $(\mathrm{ICH})$, many case series have shown positive results with decompressive craniectomy ${ }^{8}$; however, a large randomized controlled trial failed to demonstrate improved outcomes when decompressive craniectomy was compared to aggressive medical management. ${ }^{21}$ Newer surgical techniques using stereotactic and endoscopic clot thrombolysis have shown benefit over medical management alone and randomized controlled trials are currently ongoing. ${ }^{22-25}$ Currently surgery is advocated in $\mathrm{ICH}$ patients with GCS 6-12, deteriorating neurological examination, lobar $\mathrm{ICH}$, infratentorial $\mathrm{ICH}$ greater than $3 \mathrm{~cm}$ in diameter (or those hemorrhages 
less than $3 \mathrm{~cm}$ in diameter but with significant mass effect with brainstem compression), ventricular obstruction or extension, hydrocephalus, cerebellar vermis involvement, superficial hemorrhage, clot volume $20-80 \mathrm{~mL}$, relatively young patients, and hemorrhage resulting in midline shift or increased ICP. ${ }^{8,26-28}$ While decompressive craniectomy can be lifesaving on patients with $\mathrm{AlH}$, it has varying effects on long-term functional outcome.

\section{Step 2. Sedation}

Adequate sedation is an often-overlooked therapy in the treatment of $\mathrm{AlH}$. It is not uncommon to see patients in neuro-ICU with high ICP and submaximal dose of sedating medications. Patients with agitation and ventilator dyssynchrony result in increased intrathoracic pressure leading to decreased venous return from the head and increased ICP. Furthermore, agitation raises the systemic arterial pressure, which can result in increased ICP in patients on the extreme of their autoregulatory curve. For these reasons, agitated patients with elevated ICP should be sedated to a quiet motionless state. Additionally, they should not undergo neurologic examinations every 10 minutes in which noxious stimuli can raise the ICP. Choice of sedatives should focus on short-acting agents such that they can be stopped quickly when a neurological examination is necessary. Generally first-line agents include a sedativehypnotic and an analgesic agent. In patients that are hemodynamically stable with euvolemic intravascular volume state, propofol in bolus doses followed by a continuous intravenous infusion can provide adequate sedation. It is not uncommon to see serious hypotension that occurs in IV propofol infusion particular if given to elderly patients who are volume depleted. Given that pain is often a contributor to elevated ICP, especially in TBI patients, the addition of fentanyl can work synergistically with propofol to reach the sedation goal. However, caution should be taken with bolus injections of opioids one can have paradoxical rises in ICP following a bolus injection of an opiate. This occurs because the opioid bolus transiently lowers the MAP which in turn raises the ICP as the cerebral blood vessels dilate to maintain cerebral blood flow (CBF). This usually occurs on patients with an intact autoregulatory system; however, it has been seen in patients with compromised autoregulation as well. ${ }^{3,29,30}$ Additionally, propofol may have some neuroprotective properties in TBI patients. One study looking at propofol versus morphine in severe TBI patients showed that the propofol treated patients had better ICP control and more favorable long-term outcomes. ${ }^{3,31}$ In hemodynamically unstable patients (i.e., hypotension, poor cardiac output, intravascular volume depletion), midazolam may be a better option given its limited effects on the heart rate and blood pressure.

\section{Step 3. Cerebral perfusion pressure optimization}

At the lower spectrum of the autoregulatory curve, the CPP is low and there is a compensatory dilation of the intracerebral arterioles, which increases blood volume and subsequently increases ICP. In this scenario, augmentation of the MAP with a vasopressor medication (e.g., phenylephrine, norepinephrine) will raise the CPP leading to mild arteriolar vasoconstriction with decreased blood volume and decreased ICP. It is unclear what the lower limit of CPP is below which, ICP begins to rise. This varies patient to patient and is generally higher in patients with chronic hypertension where the autoregulatory curve is shifted to the right. In TBI patients, the BTF recommends systolic blood pressure (SBP) $\geq 100 \mathrm{mmHg}$ for patients aged 50-69 years and $\mathrm{SBP} \geq 110 \mathrm{mmHg}$ for patients aged $15-49$ years or $>70$ years. ${ }^{12}$ Their CPP goal recommendation is between 60 and $70 \mathrm{mmHg} .^{12}$

Alternatively, if MAP and ICP are elevated in a sedated patient, mild reduction in the MAP may lead to a reduction in the ICP as well. If MAP is $>110 \mathrm{mmHg}$ and ICP is $>20$ $\mathrm{mmHg}$, systemic blood pressure should be carefully lowered using a short-acting, titratable agent (e.g., labetalol or nicardipine). It is important not to decrease the (PP so much that the intracerebral arterioles dilate resulting in reflex increased ICP as discussed in the previous paragraph. As such, generally nitroprusside is not used to treat systemic hypertension in patients with increased ICP due to the concern for direct intracerebral vasodilation and subsequent ICP elevation. 


\section{Step 4. Hyperventilation and vasoconstriction}

Hyperventilation results in a respiratory alkalosis with an elevated $\mathrm{pH}$ and reduced $\mathrm{PaCO}_{2}$. In the setting of increased $I C P$, the goal should be to lower the $\mathrm{PaCO}_{2}$ to $30 \mathrm{mmHg}$, or 25-30 mmHg in extreme cases. This reduction in $\mathrm{PaCO}_{2}$ leads to vasoconstriction of the intracerebral arterials and subsequent reduction in ICP. The peak effect is reached within 30 minutes of starting hyperventilation therapy. Over the next 1-3 hours however, the effect diminishes as the buffering capacity of the CSF compensates. ${ }^{3,32}$ Therefore, hyperventilation should only be used transiently as a temporizing measure while alternative treatments are being explored. Furthermore, it is postulated that severe hyperventilation $\left(\mathrm{PaCO}_{2}<25 \mathrm{mmHg}\right.$ ) leads to cerebral ischemia due to extreme vasoconstriction of the intracerebral arterioles. One study evaluating TBI patient observed poorer outcomes in patients prophylactically hyperventilated to $\mathrm{PaCO}_{2}$ of $20 \mathrm{mmHg}$ compared to patients ventilated normally. ${ }^{33}$ Prolonged, prophylactic, and/or profound hyperventilation are discouraged. ${ }^{8,12}$ So while harmful with prolonged use, hyperventilation is life saving in patients with acutely elevated ICP as a temporary therapy. ${ }^{34}$

Hyperventilation, although it is listed as "step number 4", it could be simultaneously initiated as steps 1 through 3 are all being instituted.

\section{Step 5. Osmotherapy}

After surgical intervention, adequate sedation and hyperventilation step fail to control ICP and optimize CPP, the next immediate step would be to initiate osmotherapy. IV mannitol 1-1.5 g/kg solution infused over 30 minutes is reasonable and may repeat it every 6 hours as needed in order to achieve the target ICP parameter. The initial dose of IV mannitol-especially in the setting of ICP crisis- should not be under-dosed. It is however, not unreasonable to give less than $1 \mathrm{~g} / \mathrm{kg}$ for the subsequent mannitol doses. For example, $50-75 \mathrm{gm}$ every 6 hour for a $70 \mathrm{~kg}$ man is acceptable after the initial $1.5 \mathrm{gm} / \mathrm{kg}$ (e.g. $105 \mathrm{~g}$ for a 70 $\mathrm{kg}$ man) bolus. Alternatively, one may give IV hypertonic saline (HTS). There are different concentrations available: $2 \%, 3 \%, 23.4 \%$, ect. In an acute setting where ICP is unacceptably high with impending brainstem herniation, it makes no sense to start $2 \% \mathrm{NaCl}$ HTS infusion without any bolus at $50 \mathrm{~mL} / \mathrm{h}$. Such therapy would take days to drive up the sodium and patient might not survive for such duration of time. Therefore in emergency situations, it is wise to choose a small volume (hence more rapid infusion) and higher concentration (e.g. 23.4\%) given as IV push over 15 minutes. ${ }^{35,36}$ Not every case requires such an aggressive osmotic therapy. An elderly patient, for whom clinicians and families have decided against decompressive hemicraniectomy, who is still awake with significant mass effect and midline shift from malignant middle cerebral artery infarction might only need mild-moderate osmotic effect in order to avoid herniation. In such situation, it may be reasonable to opt for a less concentration HTS (e.g. 2-3\% HTS at $50 \mathrm{~mL} / \mathrm{h}$ continuous infusion) and "drive up" the sodium over 1-2 days rather over the next 2 hours. A reasonable target serum sodium concentration in above scenario would be 150-155 mEq/L just during the herniation watch period. The decision as to mannitol versus hypertonic saline as the choice of osmotherapy depends on patient's renal condition and intravascular volume status. For those with normal renal function and euvolemic state, either option would lead to significant reduction in ICP. Typically, mannitol should not be used for patients who are hypotensive with sinus tachycardia due to prerenal dehydration as osmotic diuresis would worsen hypotension.

\section{Step 6. Hypothermia and targeted temperature modulation}

It is well known that hypothermia with temperature maintenance at 33 degrees Celsius leads to reduction in ICP. Whether hypothermia is truly neuroprotective or not in brain injured patients is not clear at this time, however. The only class I evidence so far for improving neurological, functional outcomes is the use of hypothermia after out-ofhospital ventricular fibrillation and ventricular tachycardia cardiac arrest. ${ }^{37}$ Recently, this data is being reinvestigated after 36 degrees Celsius had the same outcome compared to 33 degrees Celsius. ${ }^{38}$ For patients with high ICP, hypothermia has shown consistent findings: it lowers ICP but does not confer improved long term outcomes. ${ }^{39}$ Some of 
these studies skipped essential early step (i.e. osmotherapy) for reducing ICP and hence may not accurately reflect the real life experience of the benefit that hypothermia might provide. Nevertheless, there is no class I evidence that reducing body temperature improves long term outcome. But again, hypothermia does reduce ICP and it may be used to optimize CPP as one of the more aggressive management strategies.

What is more important at the bedside is probably recognizing the limitations and serious adverse events that are associate with hypothermia especially if used for a prolonged period of time. Hypokalemia (relative hypokalemia as the total body potassium level is likely the same- it is the into-the-cell shift leading to a low plasma concentration of potassium), atrial and ventricular arrhythmias, hypotension may occur. The negative hemodynamic effect is not trivial. There may be also tendency for coagulopathy as well as significantly elevated risk of infection, particularly ventilator associated and nosocomial pneumonia. ${ }^{40}$

\section{Step 7. Barbiturate coma}

The use of pentobarbital coma has clearly fallen out of favor in recent years, and this is due to its inevitable and unacceptably serious side effects. Pupils may become fixed and dilated. Its negative, cardiac suppressive effect leads to severe hypotension and increase in vasopressor requirements. An increase in systemic vascular resistance caused by the use of high dose vasopressors may lead to end organ hypoperfusion and significant metabolic acidosis. A severe metabolic acidosis makes vasopressors to become ineffective and cause refractory hypotension which leads to even further increase in pressor requirements. A vicious cycle like this may lead to cardiac arrest and death. Therefore in routine intensive care unit setting for intracranial hypertension, this medical therapy has either disappeared or remains as one of the last resort therapies. In certain neurosurgical emergencies such as intraoperative rupture of intracranial vessels (e.g. arteriovenous malformation resection surgery with intraoperative rupture) with super refractory ICP, a rapid bolus of IV pentobarbital injection may provide effective reduction in pressure. However, a prolonged use of IV pentobarbital drip is generally not recommended any more.

\section{REFERENCES}

1. Marmarou A, Anderson RL, Ward JD, Choi SC, Young HF, Eisenberg HM, et al. Impact of ICP instability and hypotension on outcome in patients with severe head trauma. / Neurosurg 1991;75:S59-66.

2. Cremer OL, van Dijk GW, van Wensen E, Brekelmans G], Moons KG, Leenen LP, et al. Effect of intracranial pressure monitoring and targeted intensive care on functional outcome after severe head injury. Crit Care Med 2005;33:220713.

3. Mayer SA, Chong JY. Critical care management of increased intracranial pressure. J Intensive Care Med 2002;17:55-67.

4. Balestreri M, Czosnyka M, Hutchinson P, Steiner LA, Hiler $M$, Smielewski $P$, et al. Impact of intracranial pressure and cerebral perfusion pressure on severe disability and mortality after head injury. Neurocrit Care 2006;4:8-13.

5. Steiner $T$, Ringleb P, Hacke W. Treatment options for large hemispheric stroke. Neurology 2001;57(Suppl 2):S61-8.

6. Becker DP, Miller JD, Ward JD, Greenberg RP, Young HF, Sakalas R. The outcome from severe head injury with early diagnosis and intensive management. / Neurosurg 1977; 47:491-502.

7. Qureshi Al, Geocadin RG, Suarez II, Ulatowski JA. Long-term outcome after medical reversal of transtentorial herniation in patients with supratentorial mass lesions. Crit Care Med 2000;28:1556-64.

8. Latorre JG, Greer DM. Management of acute intracranial hypertension: a review. The Neurologist 2009;15:193-207.

9. Mayhall CG, Archer NH, Lamb VA, Spadora AC, Baggett JW, Ward JD, et al. Ventriculostomy related infections: a prospective epidemiologic study. N Eng/ / Med 1984;310:553-9.

10. Sundbärg G, Nordström CH, Messeter K, Söderström $\mathrm{S}$. A comparison of intraparenchymatous and intraventricular pressure recording in clinical practice. / Neurosurg 1987;67:841-5.

11. Levin AB. The use of a fiberoptic intracranial pressure monitor in clinical practice. Neurosurgery 1977;1:266-71.

12. Carney N, Totten A, O’Reilly C, Ullman JS, Hawryluk GW, Bell 
MJ, et al. Guidelines for the Management of Severe Traumatic Brain Injury, 4th ed. Available at: www.braintrauma.org/ uploads/13/06/Guidelines_for_Management_of_Severe_ TBI_4th_Edition.pdf. Accessed at September, 2016.

13. McKinley BA, Parmley CL, Tonneson AS. Standardized management of intracranial pressure: a preliminary clinical trial. J Trauma 1999;46:271-9.

14. Guerra WK, Gaab MR, Dietz H, Mueller JU, Piek J, Fritsch MJ. Surgical decompression for traumatic brain swelling: indications and results. / Neurosurg 1999;90:187-96.

15. Subramaniam S, Hill MD. Massive cerebral infarction. Neurologist 2005; 11:150-60.

16. Yang XF, Yao Y, Hu WW, Li G, Xu JF, Zhao XQ, et al. Is decompressive craniectomy for malignant middle cerebral artery infarction of any worth? I Zhejiang Univ Sci B 2005;6:644-9.

17. Carter BS, Ogilvy CS, Candia G), Rosas HD, Buonanno F. One-year outcome after decompressive surgery for massive nondominant hemispheric infarction. Neurosurgery 1997:40:1168-75; discussion 1175-6.

18. Curry WT Jr, Sethi MK, Ogilvy CS, Carter BS. Factors associated with outcome after hemicraniectomy for large middle cerebral artery territory infarction. Neurosurgery 2005;56:68192; discussion 681-92.

19. Yao Y, Liu W, Yang X, Hu W, Li G. Is decompressive craniectomy for malignant middle cerebral artery territory infarction of any benefit for elderly patients? Surg Neurol 2005;64:1659; discussion 169.

20. Kilincer C, Asil T, Utku U, Hamamcioglu MK, Turgut N, Hicdonmez $\mathrm{T}$, et al. Factors affecting the outcome of decompressive craniectomy for large hemispheric infarctions: a prospective cohort study. Acta Neurochir (Wien) 2005;147:58794; discussion 594.

21. Mendelow AD, Gregson BA, Fernandes HM, Murray GD, Teasdale GM, Hope DT, et al. Early surgery versus initial conservative treatment in patients with spontaneous supratentorial intracerebral haematomas in the international surgical trial in intracerebral haemorrhage (STICH): a randomised trial. Lancet 2005;365:387-97.

22. Coraddu M, Floris F, Nurchi G, Meleddu V, Lobina G, Marcucci M. Evacuation of traumatic intracerebral haematomas using a simplified stereotactic procedure. Acta Neurochir (Wien) 1994;129:6-10.

23. Auer LM, Deinsberger W, Niederkorn K, Gell G, Kleinert R, Schneider $G$, et al. Endoscopic surgery versus medical treat- ment for spontaneous intracerebral hematoma: a randomized study. J Neurosurg 1989;70:530-5.

24. Barrett RJ, Hussain R, Coplin WM, Berry S, Keyl PM, Hanley $D F$, et al. Frameless stereotactic aspiration and thrombolysis of spontaneous intracerebral hemorrhage. Neurocrit Care 2005;3:237-45.

25. Vespa P, McArthur D, Miller C, O'Phelan K, Frazee J, Kidwell $\mathrm{C}$, et al. Frameless stereotactic aspiration and thrombolysis of deep intracerebral hemorrhage is associated with reduction of hemorrhage volume and neurological improvement. Neurocrit Care 2005;2:274-81.

26. Hemphill JC, Greenberg SM, Anderson CS, Becker K, Bendok BR, Cushman M, et al. Guidelines for the management of spontaneous intracerebral hemorrhage: a guideline for healthcare professionals from the American Heart Association/American Stroke Association. Stroke 2015;46:2032-60.

27. Siddique MS, Mendelow AD. Surgical treatment of intracerebral haemorrhage. Br Med Bull 2000;56:444-56.

28. Kase C. Cerebellar hemorrhage. Newton, MA: ButterworthHeinemann 1994.

29. Albanese J, Viviand X, Potie F, Rey M, Alliez B, Martin C. Sufentanil, fentanyl, and alfentanil in head trauma patients: a study on cerebral hemodynamics. Crit Care Med 1999;27:407-11.

30. de Nadal M, Ausina A, Sahuquillo J, Pedraza S, Garnacho A, Gancedo VA. Effects on intracranial pressure of fentanyl in severe head injured patients. Acta Neurochir Supp/ 1998;71:10-2.

31. Kelly DF, Goodale DB, Williams I, Herr DL, Chappell ET, Rosner MJ, et al. Propofol in the treatment of moderate and severe head injury: a randomized, prospective double-blinded pilot trial. J Neurosurg 1999;90:1042-52.

32. Ropper AH, Rockoff MA. Physiology and clinical aspects of raised intracranial pressure. In: Ropper AH, ed. Neurological and neurosurgical intensive care, 3rd ed. Philadelphia: Lippincott-Raven 1993;11-28.

33. Muizelaar JP, Marmarou A, Ward JD, Kontos HA, Choi SC, Becker DP, et al. Adverse effects of prolonged hyperventilation in patients with severe head injury: a randomized clinical trial. / Neurosurg 1991;75:731-9.

34. Robertson C. Every breath you take: hyperventilation and intracranial pressure. Cleve Clin J Med 2004;71(Suppl 1):S14-5.

35. Piper B], Harrigan PW. Hypertonic saline in paediatric traumatic brain injury: a review of nine years' experience with 23.4\% hypertonic saline as standard hyperosmolar therapy. Anaesth Intensive Care 2015;43:204-10. 
36. Lewandowski-Belfer J), Patel AV, Darracott RM, Jackson DA, Nordeen JD, Freeman WD. Safety and efficacy of repeated doses of 14.6 or $23.4 \%$ hypertonic saline for refractory intracranial hypertension. Neurocrit Care 2014;20:436-42.

37. Hypothermia after Cardiac Arrest Study Group. Mild Therapeutic Hypothermia to Improve the Neurologic Outcome after Cardiac Arrest. N Engl / Med 2002;346:549-56.

38. Nielsen N, Wetterslev I, Cronberg T, Erlinge D, Gasche Y, Hassager $C$, et al. Targeted temperature management at $33^{\circ} \mathrm{C}$ versus $36^{\circ} \mathrm{C}$ after cardiac arrest. N Engl / Med 2013:369:2197-206.

39. Andrews PJ, Sinclair HL, Rodriguez A, Harris BA, Battison CG, Rhodes JK, et al. Hypothermia for intracranial hypertension after traumatic brain injury. N Engl / Med 2015;373:2403-12.

40. Broessner G, Fischer M, Lackner P, Pfausler B, Schmutzhard E. Complications of hypothermia: infections. Crit Care 2012;16(Suppl 2):A19. 